\title{
O SETOR AVÍCOLA NO BRASIL E SUA DISTRIBUIÇÃO REGIONAL
}

\section{THE POULTRY SECTOR IN BRAZIL AND ITS REGIONAL DISTRIBUTION}

\author{
Franciele Thais Tremea ${ }^{1}$ \\ Ariana Cericatto da Silva ${ }^{2}$
}

\section{RESUMO}

A produção nacional de frango de corte tem se destacado entre os demais setores produtivos nas últimas décadas. O exponencial desempenho do setor possibilitou ao Brasil assumir posição de destaque no ranking mundial, como o maior exportador e terceiro maior produtor de carne de frango. Apesar de todos os estados brasileiros produzirem carne de frango, a produção está concentrada na região Sul do país, sendo o Paraná o principal produtor e exportador. Nesse cenário, este artigo teve como principal objetivo a análise da evolução da produção avícola no Brasil no período de 1995 a 2015. Para isso a análise da especialização da produção de frango de corte foi feita através do Quociente Locacional (QL) e a análise da concentração produtiva das exportações foi feita por meio do Market-Share (MS). Os principais resultados obtidos apontam que o avanço da tecnologia na produção, melhoramento dos índices de conversão alimentar, genética, entre outros, contribuíram para a evolução do setor, tanto em termos de produção quanto em exportação. Neste sentido a região Sul é a mais desenvolvida e especializada neste segmento. O sistema de contrato de integração facilitou o elo entre produtores rurais e agroindústria, com o fornecimento da matéria-prima e assistência técnica, e o produtor com a mão de obra e estrutura necessária.

PALAVRAS-CHAVE: Setor avícola. Especialização da produção. Exportação de carne de frango.

\section{ABSTRACT}

The national production of broiler chicken has been outstanding among the other productive sectors in the last decades. The exponential performance of the sector enabled Brazil to take a leading position in the world ranking, as the largest exporter and third largest producer of chicken meat. Although all Brazilian states produce chicken meat, production is concentrated in the Southern Region of the country, with Paraná being the main producer and exporter of poultry in the country. In this scenario, this article had as main objective the analysis of the evolution of the poultry production in Brazil from 1995 to 2015, for that the analysis of the specialization of the production of broiler chicken was made through the Locational Quotient (QL) and the analysis of the productive concentration of the exports was made through MarketShare (MS). The main results obtained indicate that the advances in technology in production, improvement of feed conversion, genetic indexes, among others, contributed to the evolution

\footnotetext{
1 Graduada em Ciências Econômicas pela Universidade Estadual do Oeste do Paraná- UNIOESTE. Email : fran tremea@hotmail.com

2 Doutoranda em Economia pela Universidade Federal de Uberlândia -UFU. Mestra em Desenvolvimento Regional e Agronegócio pela Universidade Estadual do Oeste do Paraná -UNIOESTE- e é graduada em Ciências Econômicas pela Universidade Estadual do Oeste do Paraná-UNIOESTE. E-mail : ariana cericatto@hotmail.com
} 
of the sector, both in terms of production and exports. In this sense, the South region is the most developed and specialized in this segment. The integration contract system facilitated the link between rural producers and agribusiness, with the supply of raw material and technical assistance, and the producer with the necessary manpower and structure.

KEYWORDS: Poultry industry. Production Specialization. Export of chicken meat.

JEL Code: D23; Q13; R12.

\section{INTRODUÇÃO}

A produção de frango de corte impressiona pelo seu dinamismo e pela competência. $\mathrm{O}$ Brasil se destaca em relação ao ganho de produtividade associado à coordenação da cadeia avícola, ocupando o primeiro lugar dos países exportadores e terceiro maior produtor mundial. A carne de frango brasileira é exportada para mais de 150 países, e em 2013 a participação do Brasil no comércio mundial de carne de frango foi de $36,60 \%$ a 31,33\% de participação dos Estados Unidos, segundo maior exportador (MINISTÉRIO DA AGRICULTURA, PECUÁRIA E ABASTECIMENTO MAPA, 2014).

Para Buarque (2008), a indústria brasileira de aves se desenvolveu buscando novos produtos, diversificando a oferta e agregando valor às matérias-primas na busca por novos segmentos de mercado. A melhoria nas técnicas de manejo e a modernização tecnológica resultaram em aumentos expressivos de eficiência da produção.

A produção de frango de corte vem ganhando espaço tanto em pequenas, médias ou grandes propriedades, principalmente, pelo sistema de integração em que o produtor possui parceria com a agroindústria facilitando o processo desde a engorda até a venda do frango de corte, na busca da melhora na qualidade do produto ofertado e o ganho da produção.

Além disso, o setor avícola brasileiro emprega aproximadamente quatro milhões de pessoas de forma direta e indireta, o que correspondia por $1,5 \%$ do Produto Interno Bruto (PIB) no ano de 2013 e esta atividade está presente em todos os estados do Brasil, sendo a região Sul a que se destaca com $46 \%$ da produção brasileira (UNIÃO BRASILEIRA DE AVICULTURA - UBA, 2014).

Em função de toda esta dinâmica no sistema agroindustrial de frango de corte faz-se a seguinte pergunta: Qual a participação regional e a concentração produtiva da produção brasileira de carne de frango? Dessa forma, este artigo teve como principal objetivo a análise da evolução da produção avícola no Brasil no período de 1995 a 2015, para isso a análise da especialização da produção de frango de corte foi feita através do Quociente Locacional (QL) e a análise da concentração produtiva das exportações foi feita por meio do Market-Share (MS).

$\mathrm{O}$ trabalho está dividido em cinco partes, sendo a primeira esta introdução. $\mathrm{Na}$ segunda encontra-se a revisão de literatura, a terceira parte refere-se aos procedimentos metodológicos, no qual são descritos os métodos, dados e variáveis que foram utilizados para a realização deste trabalho. $\mathrm{Na}$ quarta parte são apresentados os resultados e discussões, sendo abordados os seguintes assuntos: as evoluções do setor avícola brasileiro, as especializações produtivas da avicultura entre as regiões brasileiras e a participação no mercado avícola. E por fim, as considerações finais completam o trabalho. 


\section{AS TRANSFORMAÇÕES NO SETOR AVÍCOLA BRASILEIRO}

A produção avícola brasileira com fins comerciais teve seu desenvolvimento a partir do final da década de 1950, nos estados da região Sudeste, principalmente em São Paulo. Esse período foi marcado, principalmente, pelo sistema de produção artesanal conhecido como frango caipira na qual eram vendidos vivos ou já abatidos nas feiras livres. Na década de 1970, houve expansão da produção para região Sul e também um arranque tecnológico em equipamentos que melhoraram desde a produção dos ovos e pintainhos até a fabricação de ração, fazendo com que houvesse uma melhora no resultado final da carne de frango e contribuindo para uma produção em escala, surgindo o sistema de integração (SAKOMURA, 2014).

Em 1975, conforme Sakomura (2014), iniciaram-se as exportações brasileiras e houve o equilíbrio de oferta e demanda da carne de frango. Em 1980, o excesso de alojamentos de frango acarretou em 1981 o excesso de produção, e o país entrou em recessão, ocasionando ociosidade no setor. De 1981 a 1984, a crise levou a desativação de $20 \%$ da estrutura produtiva, que só voltou ao equilíbrio em 1985 . No ano de 1986 entrou em vigor o Plano Cruzado e com o déficit no abastecimento de carne bovina houve uma alta na oferta avícola. Apesar das crises até os anos 2000, o crescimento foi em torno de 8 a 10\% ao ano. Em 2002, o país abateu cerca de 7,43 milhões de toneladas de carne e exportou aproximadamente 1,6 milhões de toneladas de frango.

Segundo França e Fernandes Filho (2003), em 2003 o mundo estava em crise em decorrência do endividamento dos EUA no pós-guerra com o Iraque. Na Europa a crise afetou a produção de carne de frango em detrimento dos altos custos de produção e a concorrência com os produtos provenientes do Brasil e na Tailândia. Houve a perda dos mercados tradicionais da Rússia e aumento do protecionismo no mercado das carnes de frango. O Brasil que exportava 300 mil toneladas de carne para a Rússia passou a exportar apenas 33,33 mil toneladas por ano, devido à queda do consumo e as restrições do mercado externo. Com esta conjuntura, houve excesso de oferta de carne de frango no mercado, ocasionando a queda no preço final e prejudicando o produtor. Apesar da crise no setor financeiro, não houve queda na produção, novos mercados foram explorados como China, Canadá e países do MERCOSUL.

A descoberta da gripe aviária (Influenza H5N1) em 2006 na África, Ásia e Europa levou a queda na procura de carne de frango pelo mercado mundial e a alta produção no mercado interno levou a uma redução no preço do frango abatido, cerca de $30 \%$ no primeiro trimestre. $O$ câmbio sobrevalorizado e o embargo russo às carnes brasileiras também influenciaram nessa conjuntura (FACHINELLO; FERREIRA FILHO, 2010). Em 2008, a nova crise mundial com a quebra do setor bancário, a venda de carne de frango para a Europa caiu cerca de 15\%. As empresas desse ramo de atividade trabalharam o ano de 2009 em déficit e o faturamento das exportações sofreu uma queda de $16,33 \%$ em relação ao mesmo período do ano anterior, perda de aproximadamente US\$1 bilhão em receita (UBA, 2010).

A produção brasileira de carne de frango teve um rápido desenvolvimento e elevou a posição do Brasil como um dos principais produtores e exportadores desta proteína. O aumento da competitividade entre as empresas fez deste setor um dos segmentos com maior impacto sobre o desenvolvimento do Brasil pela geração de empregos, renda e tributos, os quais estimulam as demais atividades dentro e fora da 
cadeia produtiva. A avicultura brasileira correspondia a $40 \%$ da produção de carne mundial, com receita de US\$3,5 bilhões decorrente das exportações. Em 2011, 0 Brasil atingiu a marca histórica de 13,06 milhões de toneladas de carne de frango, estando entre os três maiores produtores mundiais (UBA, 2014).

A produção de aves está presente em todos os estados brasileiros, principalmente nos estados do Sul e Sudeste. Segundo dados do IBGE de 2014, a região Sul representa $52 \%$ da produção de aves, a região Sudeste aproximadamente $19 \%$, a região Centro-Oeste $13 \%$, a região Nordeste $12 \%$ e a região Norte apenas $4 \%$. Em diversas cidades brasileiras a produção de frango é a principal atividade econômica. O principal destino da produção de carne de frango brasileira é para o mercado interno cerca de 68\% e 32\% para exportações (UBA, 2013).

Segundo dados do relatório anual da Associação Brasileira de Proteína Animal (ASSOCIAÇÃO BRASILEIRA DE PROTEÍNA ANIMAL - ABPA, 2015) a produção mundial de frango em 2014 foi de 86.077 mil toneladas de carne. Os EUA ocupam o primeiro lugar com uma produção de 17.254 mil toneladas; em segundo a China com 13.000 mil toneladas e o Brasil encontra-se na terceira colocação com 12.691 mil toneladas. Já na questão exportação mundial em 2014 foram exportadas aproximadamente 10.977 mil toneladas de carne, sendo o Brasil o maior exportador com $37 \%$ do total, seguido pelos EUA com $30 \%$.

Os fatores que mais contribuíram para o destaque da atividade avícola foram a rápida absorção dos avanços tecnológicos e a importação de linhagens de alta produtividade. Os investimentos realizados nos parques industriais, principalmente na Região Sul do Brasil, foram fundamentais para o crescimento desta atividade, cujos ganhos de peso diário quase dobraram, diminuindo o tempo de engorda das aves, além da eficiência da conversão alimentar e a redução de aves mortas.

\section{Contrato de integração no setor avícola}

A abertura das empresas para o ambiente institucional faz-se principalmente por meio de contratos, a empresa concentra-se em suas atividades de interagir, adquirir insumos, distribuir produtos, viabilizar novas tecnologias, acessar distribuidores e consumidores. O mercado identifica-se com um emaranhado de relações contratuais. Para Winter (2011), as transformações do cenário econômico mundial exigiram o aumento da eficiência, que ocasionou no aumento da competitividade entre produtores rurais e agroindústria, e foi necessária a criação de novas formas de produção, que por sua vez demandaram a utilização de novos contratos, dentre os quais os contratos de integração vertical, criados com intuito de mitigar as imperfeições do livre mercado, especialmente no tocante às oscilações dos preços no mercado agrícola.

A habilidade de diferentes estruturas de governança em responder as mudanças no ambiente competitivo é tratada no contexto da firma, sendo a flexibilidade contratual uma característica importante de contratos de longo prazo. A integração vertical internaliza as transações econômicas, tornando-as subordinadas à hierarquia, onde os custos de se transacionar nos mercados são substituídos pelos custos do monitoramento e estímulos internos associados à estrutura organizacional interna da firma. O equilíbrio entre a cooperação e a concorrência nas relações verticais determina a capacidade de um sistema em responder as externalidades, como mudança no ambiente legal, restrições impostas pelos consumidores ou ainda à introdução de uma nova tecnologia (BURANELLO, 2014). 
Segundo Buranello (2014), os contratos surgem como estruturas de amparo às transações que visam controlar a variabilidade e diminuir os riscos, gerados pelas transformações tecnológicas e organizacionais. O contrato de produção integrada é aquele em que o produtor rural integrado e agroindústria, mediante acordo, definem os objetivos, as regras da parceria, as normas técnicas e parâmetros de desempenho, os direitos e deveres, prazo de vigência do trabalho em parceria, assim como os critérios de remuneração da parte contratada. A empresa integradora garante que fornecerá ao produtor integrado pintainhos de um dia, ração, medicamentos, assistência técnica e a comercialização do produto. $O$ integrado deve fornecer galpão com os equipamentos, mão de obra e aquecimento. Na integração direta com a empresa industrial ficam quase que eliminados os efeitos diretos do mercado nas relações entre a empresa integradora e os produtores rurais.

Os contratos de integração vertical entre produtores agropecuários e empresas privadas que se relacionam são articulados para que uma unidade central de processamento, exportação ou compra que regula, antecipadamente, mediante contrato, os preços, a forma de produção, a qualidade e quantidade do produto que deseja dos produtores. Esses contratos nascem com a ideia de especialização e profissionalização da produção voltada para o mercado. Assim, para o produtor, a integração vem se tornando um sistema quase que dominante no complexo agroindustrial brasileiro e, dada à especificidade da atividade, a integração deixa de ser alternativa para se tornar exigência do mercado sobre o produtor e o industrial.

As oportunidades lucrativas do negócio dependem da existência de um sistema de coordenação capaz de transmitir informações e controles ao longo de toda a cadeia produtiva, a fim de viabilizar a nova estratégia. Esse sistema de coordenação é um conjunto de estruturas de governança que interliga os segmentos de uma cadeia produtiva. Dessa forma, os determinantes de um sistema eficiente de coordenação estão associados às características das transações que se estabelecem entre os segmentos (BURANELLO, 2014). Segundo Silva (2004, p. 69):

\begin{abstract}
Existem os processos dentro de cada etapa da cadeia produtiva que podem ser otimizados, além das relações entre clientes e fornecedores, que podem ampliar ou minimizar as incertezas do ambiente, dependendo do nível de amadurecimento dessa relação. Adicionalmente, a influência do ambiente concorrencial nos diferentes mercados também estará relacionado ao nível de amadurecimento das relações na cadeia de valor. Quanto mais sólidas forem essas relações, normalmente estabelecidas contratualmente, menores serão as incertezas ou as possibilidades de o ambiente concorrencial afetar a dinâmica do mercado.
\end{abstract}

No próximo tópico é apresentada a metodologia adotada nesse trabalho afim de se atingir os objetivos específicos propostos. O objetivo geral de analisar a evolução da produção avícola no Brasil no período de 1995 a 2015, e os específicos de analisar a especialização da produção de frango de corte a concentração produtiva das exportações.

\title{
PROCEDIMENTOS METODOLÓGICOS
}

Utilizou-se o Quociente Locacional para analisar a especialização da produção de frango de corte e, para isso, foram utilizadas as variáveis valor total da 
produção de frango e da pecuária brasileira, valor da produção de frango e da pecuária por região brasileira.

A análise do market-share foi realizada afim de verificar a concentração produtiva das exportações e, para isso, foram utilizadas as variáveis exportação nacional de carne de frango e exportação de carne de frango por região brasileira.

Foram escolhidas estas variáveis devido a disponibilidade de dados coletadas no Sistema IBGE de Recuperação Automática (SIDRA) do Instituto Brasileiro de Geografia e Estatística (IBGE) no período de 1995 a 2015, e também para verificar a especialização neste ramo por região.

\section{Matriz de informação}

Para o cálculo do Quociente Locacional, as informações foram organizadas em uma matriz, na qual cada linha mostra a distribuição total do valor da produção de frango entre as diferentes regiões brasileiras, e cada coluna mostra como o valor da produção total da pecuária de uma dada região se distribui entre o total da produção. Para a construção da matriz espacial define-se:

$V P_{i j}=$ valor da produção de frango $i$ da região $j$;

$V P_{. j}=\sum_{i} V P_{i j}=$ valor da produção total da pecuária da região $j$;

$V P_{i .}=\sum_{j} V P_{i j}=$ valor da produção de frango $i$ de todas as regiões;

$V P . .=\sum_{i} \sum_{j} V P_{i j}=$ valor da produção total da pecuária de todas as regiões.

Figura 1 - Matriz de informação

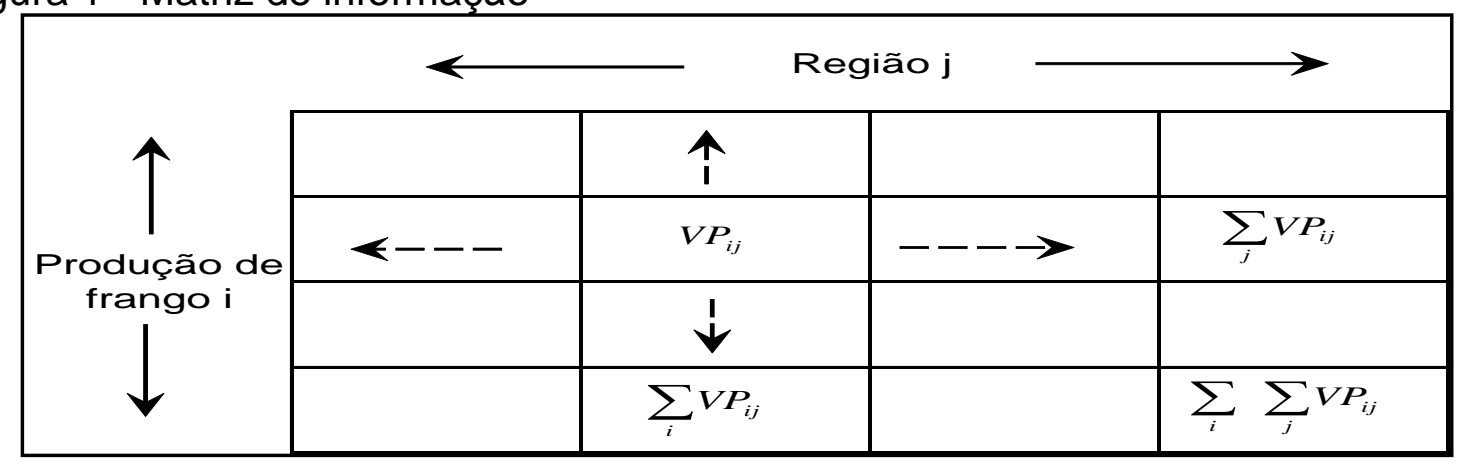

Fonte: Adaptado de Haddad (1989, p. 226).

A partir da matriz espacial são derivadas outras duas que mostram, em termos percentuais, a distribuição do valor da produção de frango em cada região brasileira, e a distribuição do valor da produção de frango entre as regiões brasileiras:

$$
\begin{aligned}
& i^{e} j=\frac{V P_{i j}}{\sum_{i} V P_{i j}} \\
& j^{e} i=\frac{V P_{i j}}{\sum_{j} V P_{i j}}
\end{aligned}
$$

sendo: $\sum_{i} i^{e} j=1,00 ; \sum_{j} j^{e} i=1,00 ; i^{e} .=\sum_{j} i^{e} j ; \mathrm{e} j^{e} .=\sum_{i} j^{e} i$ 
Franciele Thais Tremea, Ariana Cericatto da Silva

Essas matrizes fazem parte dos cálculos da medida de localização, que nesse trabalho é o quociente locacional e será detalhado na próxima seção.

\section{Quociente locacional}

O Quociente Locacional (QL) da produção de frango $i$ na região $j$ foi definido como:

$$
Q L_{i j}=\frac{V P_{i j} / V P_{i .}}{V P_{. j} / V P_{. .}}
$$

O QL compara a participação percentual de uma região, em relação ao valor da produção de frango, com a participação percentual da mesma região, em relação ao valor da produção total da pecuária no Brasil. Se o valor do quociente for maior do que 1 (um), isto significa que a região foi, relativamente, mais importante no contexto nacional, em termos do valor da produção de frango, do que em termos do valor da produção total da pecuária nacional. Assim sendo, pode-se entender QL > 1 como um indicativo de concentração da produção de frango $i$ na região $j$.

\section{Market-share}

O Market Share é uma expressão de origem inglesa, porém ela também é muito usada no Brasil e seu significado pode ser quota de mercado, fatia de mercado ou porção do mercado. O índice de Market-Share (MS) indica a participação do Brasil no total de exportações regionais de carne de frango. É definida como:

$$
M S=\frac{X_{i j}}{X_{i}}
$$

Onde:

$X_{i j}=$ exportações de carne de frango $i$ pela região $j$.

$X_{i}=$ exportações de carne de frango $i$ do Brasil.

A análise da evolução temporal deste indicador permite entender e visualizar o comportamento exportador das regiões brasileiras.

\section{RESULTADOS E DISCUSSÕES}

O agronegócio brasileiro vem sendo alvo da grande evolução tecnológica em busca da modernização de processos em busca da maior produtividade e redução de custos de produção. O investimento em novas tecnologias abrange toda a cadeia produtiva e a mudança do convencional para o novo conceito técnico é claramente visível nas propriedades rurais, sendo destaque no setor avícola.

O modelo de indústria de abate de frangos instalada no Sul do Brasil (pioneiramente em Santa Catarina), mantém um "contrato de parceria" com o produtor, este formato de produção é similar ao dos EUA e de grande parte dos principais países produtores do mundo. No Brasil, este sistema originou-se na região Sul com base na experiência das empresas do segmento de suínos (BORTOLIN, 2002). A produção de frangos de corte é cercada de tecnologia. Os aviários utilizam vários equipamentos para manter o ambiente controlado. Ao mesmo tempo, empresas 
de genética, laboratórios e fábricas de ração buscam oferecer às aves saúde e conforto, além de sustentabilidade na produção. Há ainda investimentos em automação.

O desenvolvimento da avicultura tem sido marcante, e este avanço se faz sentir principalmente no que se refere à produção de frangos de corte. O plantel avícola brasileiro cresceu em volume de produção e, principalmente, em parâmetros de produtividade. Segundo Mendes (1989), a melhor forma de avaliar o desempenho produtivo na avicultura seria a utilização de um índice que conseguisse ordenar parâmetros de avaliação técnica e econômica, que possibilitassem identificar o melhor lote e maior rentabilidade. No entanto, o autor alerta que na prática é difícil mensurar essa rentabilidade devido a variabilidade da relação dos preços dos insumos avícolas e do produto final.

Utiliza-se o Índice de Conversão Alimentar (ICA) como parâmetro mais importante na avaliação do desempenho econômico. O ICA é o consumo de ração do animal em um período de tempo/ganho de peso, quando houver uma piora no desempenho, mais ração terá sido consumida para a produção de um quilo de frango, sendo a ração o item de maior representatividade no custo de produção no geral, e o desempenho econômico depende da eficiência de transformar ração em carne. Esta evolução só foi possível devido à evolução genética das linhagens modernas associadas às novas técnicas de manejo de criação, erradicação de enfermidades, ambiência, automação de equipamentos e os avanços na nutrição (MENDES, 1989; DUARTE, 2011).

Na Tabela 1, apresenta-se a evolução média do ICA, ao se fazer uma análise da produção avícola brasileira, fica evidente o rápido desenvolvimento em função do incremento de novas tecnologias e modernização do processo produtivo que alcançou níveis elevados de produtividade.

Tabela 1 - Evolução Média dos Coeficientes de Produção de Carne de Frango

\begin{tabular}{cccc} 
Ano & Peso Frango Vivo $(g)$ & $\begin{array}{c}\text { Conversão } \\
\text { Alimentar }\end{array}$ & Idade de Abate \\
\hline 1930 & 1.550 & 3,5 & 15 semanas \\
1940 & 1.550 & 3,00 & 14 semanas \\
1960 & 1.600 & 2,25 & 8 semanas \\
1970 & 1.700 & 2,15 & 7 semanas \\
1984 & 1.860 & 2,00 & 47 dias \\
1994 & 2.050 & 1,98 & 45 dias \\
2000 & 2.250 & 1,88 & 43 dias \\
2005 & 2.300 & 1,82 & 42 dias \\
2008 & 1.250 & 1,75 & 41 dias \\
2009 & 2.440 & 1,76 & 41 dias \\
2010 & 2,300 & 1,76 & 41 dias \\
\hline
\end{tabular}

Fonte: UBA, 2010.

A evolução do ICA foi um dos grandes avanços para a avicultura de corte, em 1930 eram necessárias 15 semanas e 3,5 kg de ração para 1,55 kg de carne de 
Franciele Thais Tremea, Ariana Cericatto da Silva

frango, ao longo dos anos estes dados foram se alterando devido aos avanços genéticos e de produtividade e, em 2010, eram necessários apenas 41 dias e 1,76 kg de ração para 2,3 kg de carne de frango (TABELA 1).

Para mencionar a evolução em produtividade, destaca-se o índice de Ganho Médio Diário (GMD) maior que $50 \mathrm{~g} / \mathrm{dia}$, isto significa uma taxa de crescimento diário de no mínimo $20 \%$ superior ao peso inicial de $40 \mathrm{~g}$. O ICA também evoluiu, diminuindo a quantidade de alimento por unidade de ganho de peso, nos dias atuais sem maiores dificuldades obtêm-se um quilograma de peso vivo com não mais de 1,9 kg de ração, isto se traduz em uma eficiência alimentar superior a 50\% (DUARTE, 2011).

O grau de exigência do consumidor internacional e brasileiro por alimentos mais seguros e a exigência para a alteração dos procedimentos convencionais, fortalecidos por legislações específicas para cada país, tem forçado a indústria animal a considerar novos conceitos na utilização de aditivos para as rações. Em vários países especialmente europeus, a grande maioria destas substâncias só podem ser empregadas em caráter curativo (DUARTE, 2011).

A evolução na forma de manejo e também nos equipamentos fez com que a produção de frango se tornasse mais produtiva e lucrativa. As mudanças ocorreram em vários níveis como, por exemplo, o tipo de barracão, automatização dos equipamentos e mudanças genéticas das aves. Até os anos 2000, os sistemas utilizados eram chamados convencionais, onde se utilizava ventiladores para ventilação, maior mão de obra com baixos resultados e com comedouros e bebedouros manuais (COLUSSI, 2014).

Já a partir dos anos 2000, surgiram os sistemas de penumbra e Dark House ${ }^{3}$ que permitem o controle de luminosidade, em que o custo de implantação é mais elevado, porém possui um ambiente controlado, com conforto para as aves, melhor produtividade, sistema de automação, controle da umidade do ar e refrigeração do ambiente, a tecnologia do sistema permite ganhos como melhor conversão alimentar dos animais, menor taxa de mortalidade e redução no tempo de alojamento. Ademais, o maior rendimento é atribuído especialmente à diminuição do estresse e da agitação dos animais, além dos exaustores controlarem a temperatura, ajudam a evitar gasto de energia das aves (COLUSSI, 2014). Para França (2000), a utilização de comedouros e bebedouros automáticos tem apresentado, no Brasil, maior eficiência em termos de limpeza, melhoria no ganho de peso e redução da mortalidade das aves, além de reduzirem a frequência de pessoas no interior dos galpões.

O Gráfico 1 demonstra a evolução da produção de carne de frango brasileira para o período de 1996 a 2015, onde pode-se verificar o aumento desta produção ao longo das últimas décadas. A evolução da produção de carne de frango brasileira para o período de 1996 a 2015 mais que triplicou. Em 2011, atingiu a marca de 13.050 milhões de toneladas de carne, tendo um pequeno recuo em 2012 e 2013, voltando a crescer em 2014 e em 2015 atingiu 13.140 milhões de toneladas de carne de frango produzida. Em 1996, a produção era mais centralizada na região Sul e, no passar dos anos, foi se espraiando para as demais regiões brasileiras.

\footnotetext{
3 Instalação de criação em ambiente escuro. Leva em consideração questões de manejo e o desempenho frente ao sistema tradicional. Evita ao máximo as influências das condições externas dentro do barracão. O produtor que controla as condições dentro do barracão (NOBREGA, 2016).
} 
Gráfico 1 - Produção de carne de frango - 1996 a 2015 (em mil ton)

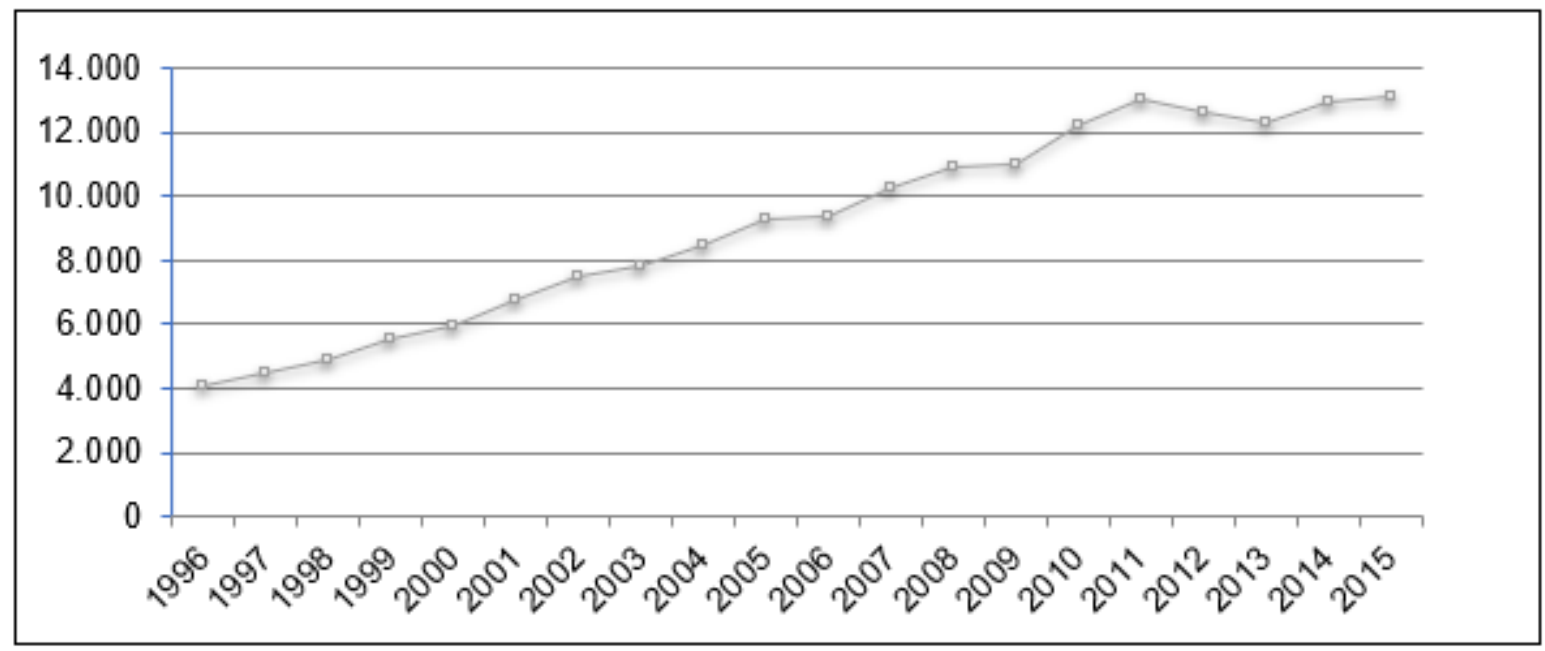

Fonte: APBA, 2016.

Além do destaque na produção e exportação, a carne de frango é a proteína mais consumida pelos brasileiros, seguida pela carne bovina e suína. Conforme dados do MAPA (2015), o consumo de carne de frango representou 43,9\% do total, seguida pela carne bovina e suína com $37,4 \%$ e $14,10 \%$, respectivamente, e as demais como peixes, carneiro entre outras representaram $4,6 \%$ do total consumido em 2015 . A carne de frango é uma das mais acessíveis para a população, sendo uma das proteínas mais baratas existentes no mercado, custando em média $R \$ 6,20 \mathrm{~kg}$. Já a carne bovina custa em média $R \$ 22,67 \mathrm{~kg}$ e a suína $R \$ 16,15$ conforme dados do Instituto de Economia Agrícola (INSTITUTO DE ECONOMIA AGRÍCOLA - IEA, 2016).

Em relação ao destino da produção brasileira de carne de frango, verifica-se através dos dados da ABPA (2016), que 68\% da produção de carne de frango é consumida internamente, sendo o restante exportado. A evolução das exportações brasileiras de carne de frango é demonstrada no Gráfico 2, sendo possível verificar a expansão das exportações da carne de frango, tanto em receita como em volume exportado.

Gráfico 2 - Exportação de carne de frango - 2004 a 2015

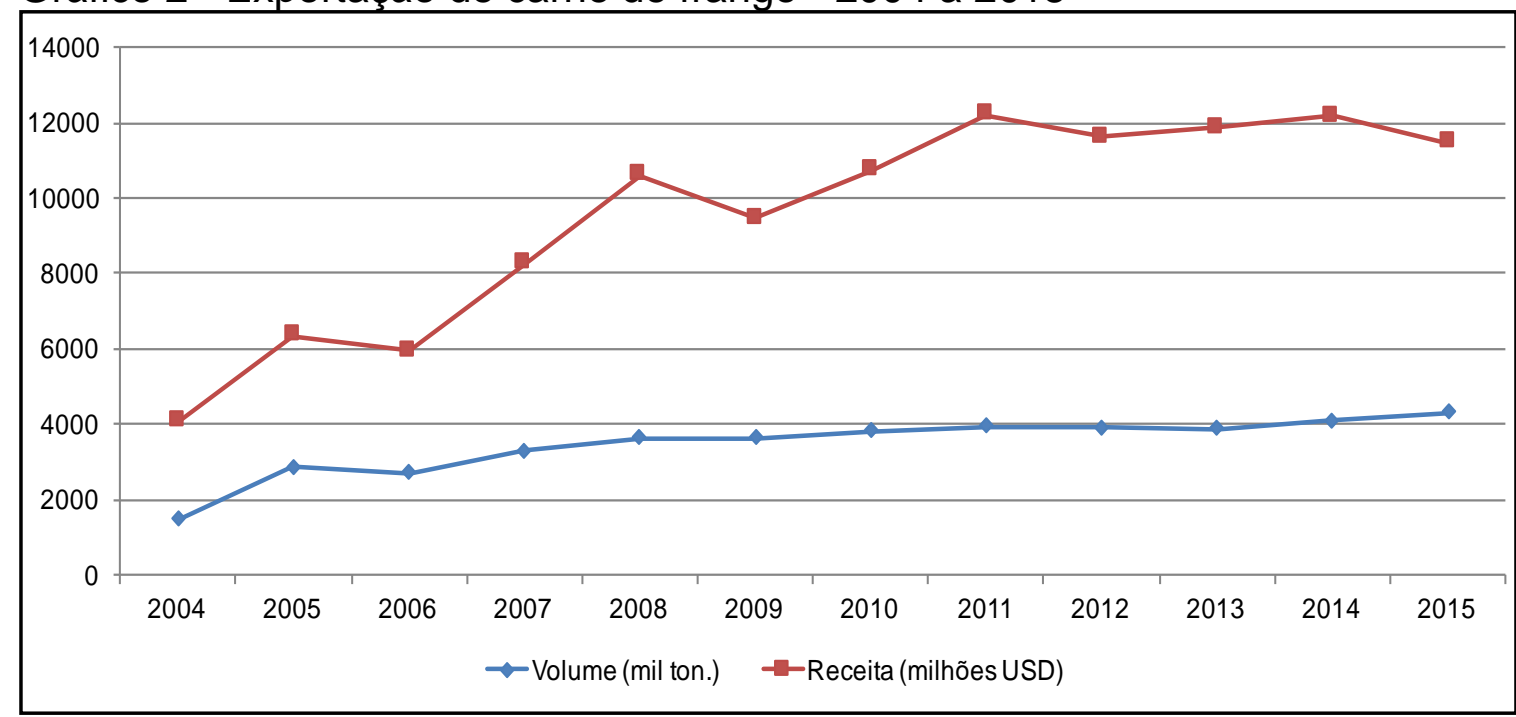

Fonte: ABPA, 2016. 
O Brasil exporta sua produção de carne de frango para todos os continentes, sendo o Oriente Médio o maior importador da carne brasileira com 1.581.422 toneladas, seguido pela Ásia com 1.232.399 toneladas, África 497.537 toneladas, União Europeia 407.440 toneladas e América 369.953 toneladas de carne de frango. Em 2004, o volume de exportação era de 1.469,7 milhares de toneladas e, em 2015, foi de 4.304,1 milhares de toneladas, maior valor atingido no período analisado. Em 2009, com o reflexo da gripe aviária, o volume das exportações caiu, o que foi sentido pelas receitas que tiveram uma queda de 16,34\% de 2008 para 2009.

Portanto, verifica-se uma grande importância da produção avícola no contexto da pecuária brasileira como um todo, gerando emprego e divisas ao país. No entanto, é pertinente a compreensão de como essa atividade se distribui ao longo do território nacional, esse assunto é tratado nos itens seguintes.

\section{Participação no mercado mundial da produção avícola por regiões brasileiras}

No decorrer dos anos de 1970 se consolidou uma forma peculiar de inserção da agricultura no comércio internacional no que se refere à composição da produção, crescimento das atividades ligadas à exportação e aumento do grau de processamento industrial dos produtos (CARNEIRO, 2002).

As indústrias de frangos se estabeleceram como um segmento moderno graças à política agrícola de crédito subsidiado e a instalação de frigoríficos, além das articulações entre grupos nacionais e empresas estrangeiras produtoras de linhagens (RIZZI, 1993).

Em 2004 o Brasil conquistou a liderança mundial nas exportações de frango, quando ultrapassou os Estados Unidos, que é o segundo maior exportador de frango de corte do mundo. A dependência da avicultura brasileira em relação ao mercado externo a coloca em vulnerabilidade, pois, numa situação de crise mundial poderá haver redução das encomendas, o que desencadearia a adoção de medidas para reduzir a produção no país. Através das políticas setoriais que elegem prioridades de governo e selecionam mecanismos de apoio voltados para o sucesso dos setores, foi possível o incremento da produção e da exportação de frangos (BELUSSO; HESPANHOL, 2010).

Conforme dados da Avisite (2015) apenas a região Sul do Brasil continua a apresentar evolução consistente na exportação de carne de frango, liderada pelo Paraná, que aumentou seu volume em quase $20 \%$, em Santa Catarina e no Rio Grande do Sul a expansão ficou, respectivamente, 0,06\% e 1,86\%. Já no CentroOeste, a forte expansão de Goiás (expansão de 16\%) teve efeito nulo sobre os resultados regionais, visto que as outras três unidades federativas, Mato Grosso do Sul, Distrito Federal e Mato Grosso, apresentaram reduções de, respectivamente, $1,6 \%, 13 \%$ e $35 \%$.

Além da região Sul, somente a região Sudeste apresentou aumento comparado ao período de 2014, com expansão de 4\% em Minas e de 31\% no Espírito Santo e, ainda, de uma pequena exportação do Rio de Janeiro. Pois São Paulo apresentou ligeiro recuo (-0,28\%). Na Região Nordeste, os três estados exportadores - Bahia, Pernambuco e Paraíba - registraram forte retração. Com isso, o volume regional recuou $28 \%$.

A partir dos resultados do Market-Share (Gráfico 3), verifica-se que houve mudança na participação das exportações de carne de frango brasileira, no ano de 2000, a Região Sul era responsável por quase $100 \%$ das exportações para o mercado 
mundial, já em 2015 verifica-se que as demais regiões passaram a ter maior representatividade no mercado mundial.

Gráfico 3 - Exportações de carne de frango por região brasileira - 2000 e 2015

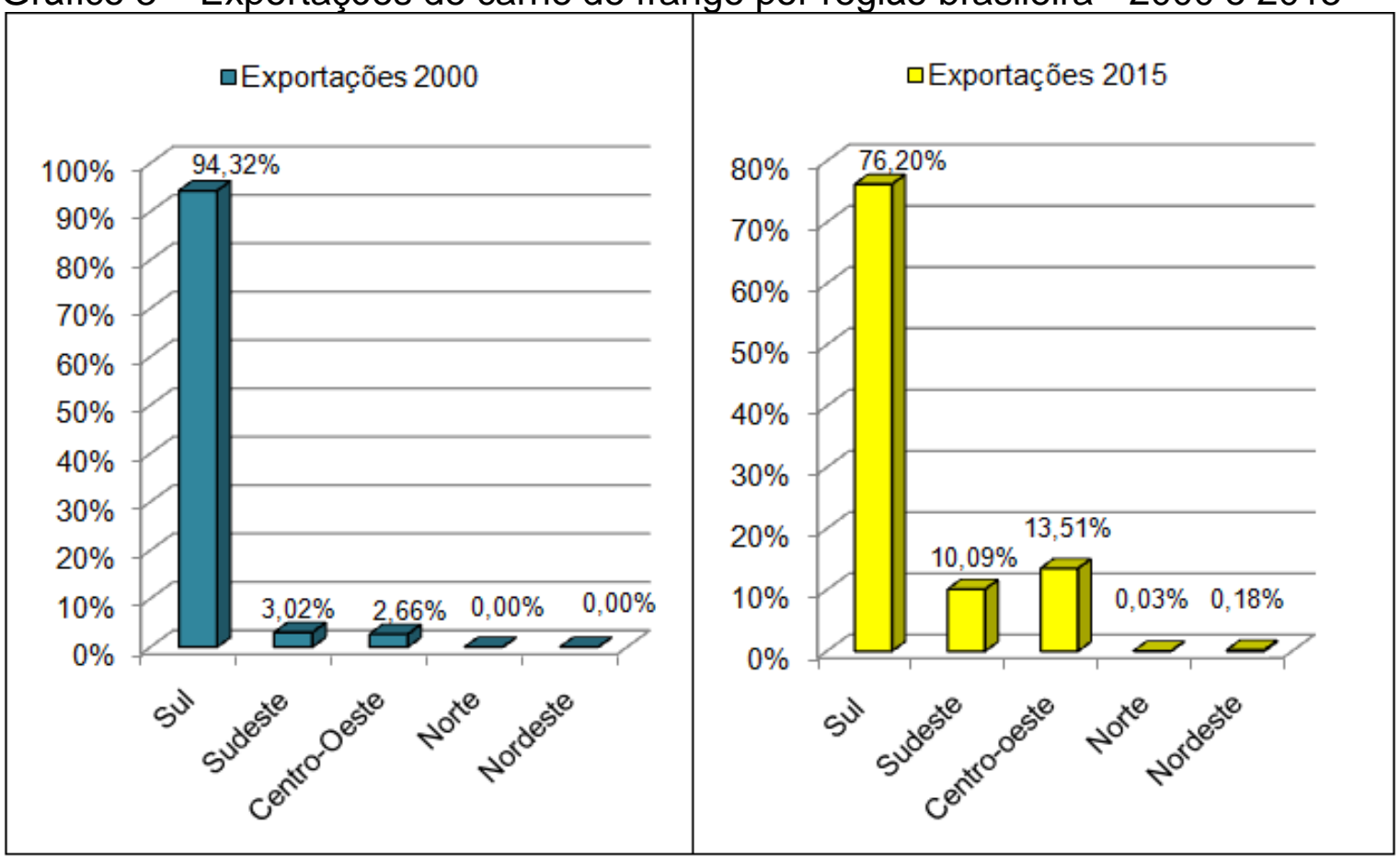

Fonte: Resultado da pesquisa com base nos dados do MAPA, 2016.

As regiões Sudeste e Centro-Oeste foram as regiões que mais evoluíram no período analisado, de $3,02 \%$ e $2,66 \%$ em 2000 para $10,09 \%$ e $13,51 \%$ respectivamente, 0 aumento nessas regiões se deve as empresas exportadoras estarem ali localizadas, como BRF e JBS no Sudeste e Bello alimentos no CentroOeste.

A região Sul continuou sendo a principal exportadora de carne de frango brasileira, em 2000 era responsável por 94,32\% e em 2015 por 76,20\%, nas regiões Norte e Nordeste a participação foi quase nula, sendo $0,03 \%$ e $0,18 \%$ respectivamente. Com a análise destes dados, pode-se verificar que além de ser a região mais especializada em relação à produção de carne brasileira, a região Sul também é a maior exportadora.

$\mathrm{Na}$ Tabela 2, encontram-se as empresas com maior representatividade no mercado da industrialização de carne de frango e exportadoras do Brasil, em primeiro lugar encontra-se a empresa Brasil Foods, seguida pela JBS e Aurora Alimentos. A maioria das sedes dessas empresas estão localizadas na região Sul e Sudeste do país, o que facilita as exportações devido aos portos de Paranaguá/PR e Santos/SP.

As empresas BRF e JBS foram responsáveis por cerca de $70 \%$ do volume exportado pelo país em 2013. A BRF, maior processadora de carne de frango do Brasil, representou $45,8 \%$ das exportações brasileiras do produto, já a JBS foi a segunda principal exportadora de carne de frango no período, com $23,8 \%$ de participação nas vendas externas (UBA, 2014). 
Franciele Thais Tremea, Ariana Cericatto da Silva

Tabela 2 - Ranking das empresas brasileiras exportadoras de frango - 2015

\begin{tabular}{llll}
\hline & & Ranking das Empresas \\
\hline $1^{\circ}$ & Brasil Foods (BRF) & $11^{\circ}$ & COOPAVEL \\
$2^{\circ}$ & JBS & $12^{\circ}$ & ZANCHETTA ALIMENTOS \\
$3^{\circ}$ & AURORA ALIMENTOS & $13^{\circ}$ & COASUL AGROINDUSTRIAL \\
$4^{\circ}$ & COPACOL & $14^{\circ}$ & IRMÃOS DALLA COSTA \\
$5^{\circ}$ & C.VALE & $15^{\circ}$ & COPAGRIL \\
$6^{\circ}$ & COOP. AGROINDUSTRIAL LAR & $16^{\circ}$ & JAGUAFRANGOS \\
$7^{\circ}$ & GT FOODS & $17^{\circ}$ & SÃO SALVADOR ALIMENTOS \\
$8^{\circ}$ & VIBRA & $18^{\circ}$ & AVERAMA ALIMENTOS \\
$9^{\circ}$ & GLOBOAVES & $19^{\circ}$ & LANGUIRU \\
$10^{\circ}$ & BELLO ALIMENTOS & $20^{\circ}$ & NOGUEIRA RIVELLI \\
\hline
\end{tabular}

Fonte: ABPA, 2016.

A presença dessas empresas na Região Sul reforça a concentração produtiva, dado que muitas dessas empresas são também integradoras, promovendo a produtividade entre os produtores rurais. Para verificar como se distribui a produção avícola no Brasil é utilizado a medida de análise regional, o Quociente Locacional, no próximo tópico.

\section{Especialização produtiva da avicultura entre as regiões brasileiras}

Historicamente, o Sul do país é uma das regiões mais tradicionais para a criação de aves no Brasil, com grande presença de cooperativas no que se refere à organização e apoio aos produtores. Granjas dessa região, assim como as do Sudeste, dependem fortemente de grãos, muitas vezes provenientes do CentroOeste. Já na região Centro-Oeste existe a dificuldade para contratação de pessoal com qualificação, pois o maior número de funcionários concentra-se nas grandes lavouras, devido à remuneração e condições de trabalho mais atrativas. Por outro lado, a produção abundante de milho e farelo de soja nessa região tem atraído integradoras, que buscam reduzir custos em um setor altamente competitivo. A opção para contornar os problemas relacionados à mão de obra está no investimento em granjas cada vez mais automatizadas (DE ZEN et al., 2014).

Por se tratar de um país de dimensões continentais e, portanto, com grande disponibilidade de áreas destinadas a produção agrícola e pecuária, fez com que o Brasil alcançasse estabilidade na produção de carnes. Sabe-se que o Brasil é o $3^{\circ}$ maior produtor mundial de milho e o $2^{\circ}$ maior produtor mundial de soja, essa grande oferta de grãos no mercado interno tem possibilitado a produção de carne com custos de produção mais baixos quando comparados a países que não produzem grandes quantidades de grãos (SILVA, 2016).

Nos estados do Sul do Brasil, com o fim da fronteira agrícola no decorrer da década de 1970, o incremento da agricultura deixou de ser extensivo e passou a depender, fundamentalmente, do aumento de produtividade e da intensificação do uso do solo, seja pela introdução de novos cultivos ou elevando o grau de integração da produção primária com a agroindústria, em especial, com a avicultura e a suinocultura (BANDEIRA, 1995). Para Rizzi (1993, p. 69), "o desenvolvimento da indústria de 
frangos na região Sul está intimamente vinculado à expansão das culturas de soja e milho" insumos básicos na composição das rações para as aves.

Verifica-se na Figura 1, que nos anos de 2005, 2010 e 2015 a região que apresentou maior especialização produtiva no setor avícola foi a Região Sul, possuindo um QL superior a um, o que indica que esta região possui especialização produtiva e maior concentração da produção em comparativo com as demais regiões.

Figura 1 - Distribuição locacional da produção avícola no Brasil - 2005, 2010 e 2015

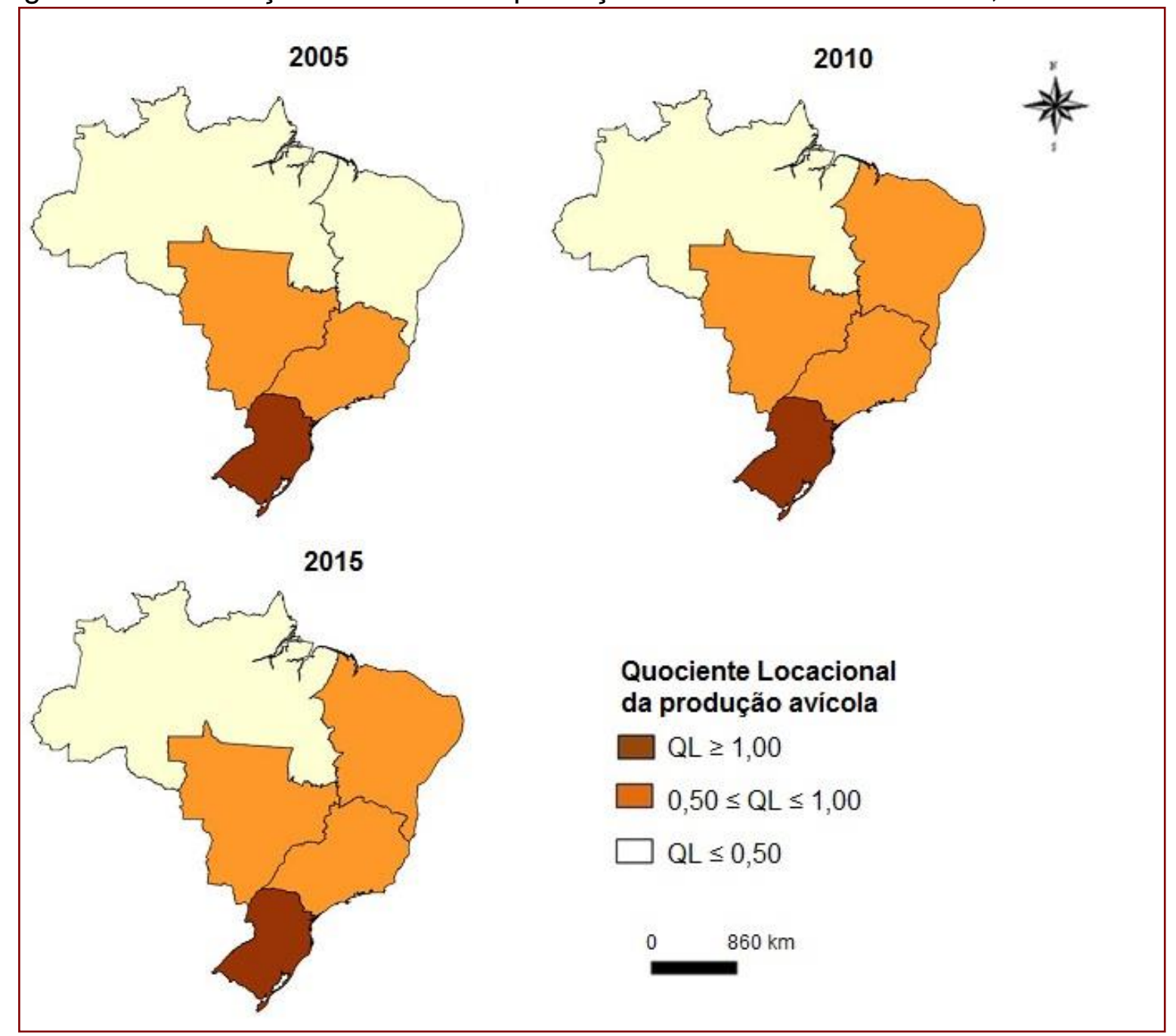

Fonte: Resultado da pesquisa com base nos dados do MAPA, 2016.

Já as regiões Centro-Oeste e Sudeste possuem especialização mediana nos três períodos analisados. A região Nordeste aumentou sua especialização produtiva, em 2005 apresentava baixa especialização e nos períodos de 2010 e 2015 passou a apresentar média especialização. A região Norte em todos os períodos analisados apresentou baixa especialização produtiva, dado que o único estado da região que possui produção de frango é o Pará.

O valor bruto da produção brasileira de carne de frango em 2005 foi de $R \$$ 28.293 milhões, em 2010 de $\mathrm{R} \$ 37.535$ e de $\mathrm{R} \$ 43.707$ milhões em 2015 , sendo que a região Sul representou $57 \%, 58,33 \%$ e 59,45\%, respectivamente, corroborando o resultado do QL que indica a região Sul como a mais especializada.

As regiões Centro-Oeste e Sudeste consideradas com média especialização (Figura 1), nos anos analisados, tiveram representações no valor bruto da produção 
Franciele Thais Tremea, Ariana Cericatto da Silva

de $10 \%$ e $26 \%$ em 2005, $13 \%$ e $23 \%$ em 2010 e $15 \%$ e $19 \%$ no ano de 2015 , respectivamente. Verifica-se que neste período a representação da região Sudeste foi regredindo em torno de $3 \%$ para cada ano, já para a região Centro-Oeste aconteceu o inverso para cada ano analisado, aumentaram cerca de $2 \%$ na representação do valor bruto da produção de aves.

Já a região Nordeste que apresentou baixa especialização produtiva na atividade avícola em 2005 possuía apenas 1\% da representação do valor bruto da produção, em 2010 quando passou a apresentar média especialização, representava $3 \%$ no valor bruto da produção e em 2015 passou para 4\%. A região Nordeste em 2005 e 2010 possuía menos de 1\% e em 2015 apenas 1\% de representação, sendo considerada como região não especializada na produção de frango de corte.

\section{CONSIDERAÇÕES FINAIS}

A avicultura de corte brasileira possui grande representação mundial. O Brasil é o maior exportador mundial, exportando para todos os continentes, e terceiro maior produtor do setor avícola. Nesse contexto, esta pesquisa teve como principal objetivo a análise da evolução da produção avícola no Brasil no período de 1995 a 2015. A análise, partiu da transformação do setor avícola brasileiro, onde inicialmente eram produzidos de forma artesanal, sem nenhuma tecnologia e eram comercializados em feiras livres, a partir da década de 1970, com o avanço da tecnologia e implantação dos contratos de integração incrementou-se o processo de produção e exportação da carne de frango.

Para a realização dessa pesquisa utilizou-se como instrumental metodológico o Quociente Locacional (QL) para a análise da distribuição do valor da produção de carne de frango e a especialização produtiva entre as regiões brasileiras. A análise do Market-Share (MS) foi utilizada para verificar a participação no mercado mundial da carne brasileira.

Verificou-se que o avanço tecnológico foi um dos principais pontos para o aumento da produção de carne de frango, estes avanços vão desde a estrutura do barracão, equipamentos e genética dos pintainhos, o que facilitou o manejo, e também a evolução dos Índices de Conversão Alimentar (ICA) e o tempo para a produção da carne, reduzido de 15 semanas em 1930 para 41 dias em 2009.

Em relação a evolução das exportações brasileiras de carne de frango segmentada por região, verificou-se que nos anos 2000 apenas a região Sul exportava sua produção para o mercado mundial, representando 94\% das exportações brasileiras. As regiões Sudeste e Centro-Oeste possuíam apenas 3\% e $2 \%$ de representação no mercado mundial. Já em 2015, assim como na produção as demais regiões passaram a ter pequenas representações.

Ao identificar a concentração produtiva na atividade avícola brasileira, utilizando o Quociente Locacional, constatou-se que a região Sul possui a maior representação e especialização da produção, o que corresponde a 59\% do valor bruto da produção de aves do Brasil, seguida pelas regiões Sudeste e Centro-Oeste, e com representação quase nula pelas regiões Nordeste e Norte.

Dessa forma, constata-se que apesar da presença de todas as regiões brasileiras na produção de carne de frango, é a região Sul que continua concentrando a maior produtividade dessa atividade, por ser a região pioneira nessa produção e por concentrar as principais empresas e integradoras. Além de possuir mão de obra qualificada para a atividade. 
Portanto, o setor agropecuário de carne de frango possui grande importância e representação na economia brasileira, destacando-se a região Sul, pioneira na produção e difusão de tecnologia na atividade. A modernização existente no sistema contribuiu para o aumento da produção, com a intensificação da especialização da produção regionalmente, o que repercutiu consequentemente nas exportações.

\section{REFERÊNCIAS}

AVISITE. Ranking avisite: as 10 maiores empresas no abate de frangos. 2015. Disponível em: https://brasilagro.wordpress.com/2015/05/08/ranking-avisite-as-10maiores-empresas-no-abate-de-frangos//. Acesso em: 21 mar. 2017.

ASSOCIAÇÃO BRASILEIRA DE PROTEÍNA ANIMAL - ABPA. Relatórios anuais 2015. Disponível em: http://abpa-

br.com.br/files/publicacoes/c59411a243d6dab1da8e605be58348ac.pdf. Acesso em 10 set. 2016.

ASSOCIAÇÃO BRASILEIRA DE PROTEÍNA ANIMAL - ABPA. Relatórios anuais 2016. Disponível em: http://abpa-

br.com.br/storage/files/versao_final_para_envio_digital_1925a_final_abpa_relatorio_ anual_2016_portugues_web1.pdf. Acesso em: 15 abr. 2017.

BANDEIRA, P. S. A economia da Região Sul. In: AFFONSO, R. de B. A.; SILVA, P. L. B. (orgs.) Desigualdades regionais e desenvolvimento. São Paulo: FUNDAP: Editora da Universidade Estadual Paulista, 1995, p. 225-251.

BATALHA, M. O. Gestão agroindustrial: GEPAI: Grupo de Estudos e Pesquisas Agroindustriais. 2 ed. São Paulo: Atlas, 1999, 323 p.

BELUSSO, D.; HESPANHOL, A. N. A evolução da avicultura industrial brasileira e seus efeitos territoriais. Maringá, 2010. Disponível em: http://www2.fct.unesp.br/nivaldo/Publica\%E7\%F5es-nivaldo/2010/AVICULTURA2010.pdf. Acesso em: 03 nov. 2017.

BORTOLIN, S. E. Estimação de equação de oferta de exportação de frango para o Brasil (1991/2000). Piracicaba/SP. (Dissertação Mestrado) - Universidade de São Paulo, Escola Superior de Agricultura “Luiz de Queiroz". 2002.

BUARQUE. S. Cadeia produtiva da avicultura: Cenários econômicos e estudos setoriais. Recife, 2008. Disponível em: http://189.39.124.147:8030/downloads/avicultura.pdf. Acesso em: 03 nov. 2017.

BURANELLO, R. Sistemas agroindustriais e contratos de integração vertical. 2014. Publicado em AgriForum. Disponível em: http://agriforum.agr.br/sistemasagroindustrias-e-contratos-de-integracao-vertical/. Acesso em: 13 jun. 2015.

CARNEIRO, R. Desenvolvimento em crise: a economia brasileira no último quarto do século XX. São Paulo: Editora Unesp, IE - Unicamp, 2002. 
Franciele Thais Tremea, Ariana Cericatto da Silva

COLUSSI, J. Sistema americano aumenta produção de aves, 2014. Disponível em: http://zh.clicrbs.com.br/rs/noticias/campo-e-lavoura/noticia/2014/11/sistemaamericano-aumenta-producao-eaves4644602.html. Acesso em: 16 out. 2017.

DE ZEN, S.; IGUMA, M. D.; ORTELAN, C. B.; DOS SANTOS, V. H. S.; FELLI, C. B. Evolução da avicultura no Brasil. Informativo CEPEA, Análise trimestral, custos de produção da avicultura. Ano 1, Ed. 1, Universidade de São Paulo, 2014.

DUARTE, K. F. Avanços em nutrição de frangos de corte e poedeiras. 2011. Disponível em: http://www.agrolink.com.br/colunistas/avancos-em-nutricao-defrangos-de-corte-e-poedeiras_3996.html. Acesso em 11 set. 2017.

FACHINELLO. A. L.; FERREIRA FILHO, J. B. S. Gripe aviária no Brasil: uma análise econômica de equilíbrio geral. 2010. Rev. Econ. Sociol. Rural, vol. 48, n. 3, Brasília, 2010. Disponível em:

http://www.scielo.br/scielo.php?script=sci_arttext\&pid=S0103-20032010000300003. Acesso em: 03 mar. 2015.

FRANÇA, L. R. A evolução da base técnica da avicultura de corte no Brasil: transformações, determinantes e impactos. Dissertação (Mestrado em Desenvolvimento Econômico), Uberlândia, 2000. Disponível em: http://levy.blog.br/arquivos/artigo-download/downs-33-0.pdf. Acesso em: 04 out. 2017.

FRANÇA, L. R.; FERNANDES FILHO, J. F. A evolução da avicultura de corte em Goiás. In: PEREIRA, S. L. O agronegócio nas Terras de Goiás. Uberlândia: EDUFU, 2003.

GRAZIANO DA SILVA, J. F. O Progresso técnico na agricultura. Campinas: UNICAMP/IE. 1990. Disponível em: https://seer.sct.embrapa.br/index.php/cct/article/viewFile/9119/5161. Acesso em 04 out. 2017.

HADDAD, P. R.; ANDRADE, T. A.; Métodos de Análise Regional. In: HADDAD, P. R. Org. Economia Regional: Teorias e Métodos de Análise. Fortaleza, Banco do Nordeste do Brasil. ETENE, 1989.

INSTITUTO DE ECONOMIA AGRíCOLA - IEA. Preços médios. 2016. Disponível em: http://ciagri.iea.sp.gov.br/nia1/precos_medios.aspx?cod_sis=4. Acesso em: 26 out. 2017.

MENDES, A. A. Curso de atualização em manejo de frangos de corte. Campinas: AONCO, 1989.

MINISTÉRIO DA AGRICULTURA, PECUÁRIA E ABASTECIMENTO - MAPA. Aves 2014. Disponível em: http://www.agricultura.gov.br/animal/especies/aves. Acesso em: 10 mai. 2017. 
MINISTÉRIO DA AGRICULTURA, PECUÁRIA E ABASTECIMENTO - MAPA. Mercado interno. 2015. Disponível em:

http://www.agricultura.gov.br/animal/mercado-interno. Acesso em: 04 out. 2016.

MINISTÉRIO DA AGRICULTURA, PECUÁRIA E ABASTECIMENTO - MAPA. AGROSTAT - Estatísticas de Comércio Exterior do Agronegócio Brasileiro, Indicadores. 2016. Disponível em:

http://indicadores.agricultura.gov.br/agrostat/index.htm. Acesso em: 10 set. 2017

NOBREGA, M. Dark house com cortina e de parede. 2016. Disponível em: http://www.resumaodeveterinaria.com.br/dark-house/. Acesso em: 05 nov. 2017.

RIZZI, A. T. Mudanças tecnológicas e reestruturação da indústria alimentar: o caso da indústria de frangos no Brasil. (Tese de Doutorado) - Universidade de Campinas. Campinas, 1993.

SAKOMURA, N. K. Avicultura. 2014. Disponível em: http://www.fcav.unesp.br/Home/departamentos/zootecnia/NILVAKAZUESAKOMURA /a ula_1_evolucaosituacao_perspectivas_da_avicultura_2013.pdf. Acesso em: 09 mai. 2015.

SILVA, C. L. da. Competitividade e estratégias internacionais: discutindo a cadeia de valor. Curitiba Juruá, 2004.

SILVA, P. F. M. da. Diagnóstico da avicultura de corte brasileira. Minas Gerais, 2016. Disponível em:

https://www.google.com.br/search?q=universidade+federal+de+lavras+\%e2\%80\%93 +3rlab\&oq=universidade+federal+de+lavras+\%e2\%80\%93+3rlab\&aqs=chrome.69i57 .33 7j0j7\&sourceid=chrome\&ie=utf-8. Acesso em: 03 nov. 2017.

SOUZA FILHO, H. M. de; BATALHA, M. O. (Org). Gestão integrada da agricultura familiar. São Carlos: EdUSCar, 2005.

UNIÃO BRASILEIRA DE AVICULTURA - UBA. Relatório anual 2010. Disponível em: http://abpa-

br.com.br/files/publicacoes/bf03265d81def3449cc962c36dabdd8d.pdf. Acesso em: 05 abr. 2017.

UNIÃO BRASILEIRA DE AVICULTURA - UBA. Relatório anual 2013. Disponível em: http://abpa-

br.com.br/files/publicacoes/732e67e684103de4a2117dda9ddd280a.pdf. Acesso em: 20 mar. 2015.

UNIÃO BRASILEIRA DE AVICULTURA - UBA. Relatório anual 2014. Disponível em: http://abpa-

br.com.br/files/publicacoes/8ca705e70f0cb110ae3aed67d29c8842.pdf. Acesso em: 22 abr. 2017.

WINTER, M. Contratos de integração vertical. São Paulo, 2011. Disponível em: http://www.agroanalysis.com.br/especiais_detalhe.php?idEspecial=86\&ordem=3. Acesso em: 13 jun. 2015. 